\title{
Time's up. Or is it? Journalists' perceptions of sexual violence and newsroom changes after \#MeToolndia
}

\author{
Chindu Sreedharan, Einar Thorsen and Ananya Gouthi
}

\begin{abstract}
The \#MeToo movement, which engulfed much of India's news and entertainment industry in October 2018, was projected by many as a watershed moment for Indian journalism. Driven largely through social media activism, it created significant media discourse and public outcry, leading to the 'outing' and resignation of scores of journalists. This paper explores the perception of \#MeToolndia in regional and national newsrooms. Drawing on Manuel Castells's ideas of networked social movement, we consider the origins of \#MeToolndia, including its mediation on private and social networks. We then draw on 190 semi-structured interviews with journalists working in 14 languages across the six administrative zones of India to explore the 'cause' of the campaign - the prevalence of sexual harassment and sexual violence in workspacesbefore turning our attention to the impact, or potential for impact, that journalists saw in it. We find most journalists felt the movement was "good", but did not think it influenced their newsroom environment or newswork in any meaningful manner. Regional journalists expressed more pessimism about the \#MeToolndia, men more so than women.
\end{abstract}

Keywords: Journalism, India, Sexual Violence, Sexual Harassment, MeToo, Social Movement

Corresponding author:

Chindu Sreedharan, W336, Faculty of Media and Communication, Bournemouth University, United Kingdom BH12 5BB. Email: csreedharan@bournemouth.ac.uk 


\section{Introduction}

\#MeToo arrived late in India, towards the end of 2018, some 11 months after actor Alyssa Milano's appeal on Twitter for women to come forward under that hashtag turned into a global campaign, and more than 11 years after Tarana Burke originally began it in a hashtagless world from "the deepest, darkest place in my soul" (Burke, undated). Notwithstanding this rather delayed start, the campaign was quick to catch on. It mobilised a significant number of activists (including journalists) and advocacy groups within weeks, and, consolidating many of its activities around the hashtag \#MeToolndia and the Twitter handle @IndiaMeToo, the campaign appropriated the media discourses on sexual violence in Indian workspaces.

The Indian beginning can be traced to an interview that former Bollywood actor Tanushree Dutta gave to Zoom TV on 25 September 2018, in which she spoke of a decade-old sexual harassment complaint she had against actor Nana Patekar. Dutta's comment, which had received very little media attention previously, was picked up by journalists this time, evoking both public support and derision. Nine days later, on 4 October, writer Mahima Kukreja levelled allegations against comedian Utsav Chakraborty on Twitter. A day later, journalist Sandhya Menon shared her experiences of sexual harassment and assault, naming senior journalists. As part of her tweets, Menon also appealed to other women to come forward with their stories, setting off a spate of public 'call-outs' of men on Twitter.

In the weeks that followed, the campaign took on the contours of a social movement organisation (McCarthy and Zald 1977, Selander and Jarvenpaa 2016), purposive and structured in its approach to engendering collective action, a coalition of journalistactivists and legal experts coming together to not just encourage women to stand up against sexual harassment, but also to lay out a support system for those who heeded their call to speak out publicly. Much of such organisational activities occurred on social networks, as did much of the heated public debates and discussions, including the 'outings' of several high-profile individuals.

The most prominent of this was that of M J Akbar, an editor who had moved into politics and was then India's junior foreign minister. On 8 October 2018, journalist Priya Ramani tweeted the 'male boss' she had referred to in an earlier article titled "To the Harvey Weinsteins of the world', published in Vogue magazine, was Akbar. Many others came forward too, to share their experiences of misconduct from Akbar while he was their editor. Akbar resigned. He also filed a defamation suit against Ramani.

Akbar was not the only one to lose his job. Several other journalists who were named resigned; many others were investigated by their employers. The movement received 
some attention from the Government of India as well. The National Commission for Women, a statutory body of the federal government, set up a dedicated email to receive complaints of sexual misconduct. Further, the government established a Group of Ministers (GoM) to recommend actions to strengthen the legal and institutional frameworks to address sexual harassment at workplaces (Wire 2018a).

Unsurprisingly, \#MeToolndia attracted much criticism. There were many who saw it as divisive, scapegoating men, and revealing "a dark side" wherein fake claims were indistinguishable from real ones (Pavani 2018). Further, it was seen as 'elitist', catering to the privileged, English-speaking, Twitter-active social classes, failing to percolate outside urban spaces to capture the experiences of women there. The movement also struggled against the backlash many women faced in the form of defamation suits from men who they had accused.

Despite these issues, the movement was seen as a 'watershed' for Indian journalism (Wire 2008b). Because of the significant number of women journalists involved, and the traction it received in the news and social media, there was a sense the activism would lead to changes in the journalistic work environment, addressing the gender issues that women had so passionately spoken out against. In this paper, we consider to what extent this happened, drawing on the largest comparative study of journalists in relation to rape and sexual violence in India. What change, if any, did \#MeToolndia bring to national and regional newsrooms?

\section{Social media, social movements, and social change}

There exists a wealth of scholarship that explores the social media 'effect' on social movements. In broad terms, and borrowing from Wolfsfeld, Segev and Sheafer (2013), this contested terrain can be divided into two sides: cyber-enthusiasts and cyberskeptics.

Cyber-enthusiasts, as the name suggests, are greatly optimistic about social media's ability to empower people to express dissent, pointing to the ability of Internet-based technologies to act as low-cost tools for information dissemination, recruitment, and resource mobilisation (Shirky 2008, Earl and Kimport 2011, Bellin 2012). A foundational argument that elucidates the dynamics of social media is rooted in the idea of a "network society", wherein ordinary people are building their own digital communities to challenge existing power relations (Castells 2008). In his later works, Castells (2012, 2015) develops this idea further, relating it to the Arab uprisings and extending the term 'networked social movements'. 
The cyber-skeptics, on the other hand, downplay the importance of digital technologies, arguing that social media smother 'real' (physical) protests by offering users 'fake' (virtual) participation in the form of easy, less-costly, and less-risky modes of online engagement. Social media promotes weak ties and activism that requires little effort (Gladwell 2010), and the 'armchair engagement' it provides for lulls sympathisers into believing they have done 'their bit', thus stopping them from any 'real' contributions (Morozov 2011). Significantly, social media can also be used by those in power against the protestors themselves (Christensen 2011, He and Warren 2011).

Cyber-realism: a middle ground Notwithstanding their overall pessimism, even the cyber-skeptics concede that social media can be influential in social movements. In the last few years, a collective of scholars have begun to occupy the middle ground between the cyber-enthusiasts and cyber-skeptics. Classifiable as 'cyber-realists', this group is more cautious in their praise of the significance of social media.

Kidd and McIntosh (2016: 792) position themselves as techno-ambivalents, allowing themselves the room to account for the "possibility of social change without presuming it to be an automatic outcome of new technology". Murthy (2013) and Gerbaudo (2012), similarly, cautions against a binary view on the power of social media. Bruns, Highfield and Burgess (2013) argue the influence of Twitter was not only "highly dependent on national and regional specificities but also considerably changeable over time". A more recent study on \#BlackLivesMatter similarly evidences, albeit with caveats, that social movements can benefit from tweeting to achieve their policy-relevant goals (Freelon, Mcllwan and Clark 2018).

Thus, there is evidence to make a case for the salience of social media in social movements. While the extent of influence these platforms can bring to bear on collective action is difficult to discern, it would be fair to make this statement: social media, under some conditions, can make some (possibly significant) contribution to social movements.

\section{Effecting social change}

Social movements seek social change, an alteration of the status quo (Jenkins 1999), to remedy a problematic situation. A key strategy for such change, which involves mounting challenges to existing power relations, is collective action (Benford and Snow 2000) - to which, as we have seen, social media have now become integral. It is useful here to look beyond the practical roles social media is known to perform during unrests, and focus, very briefly, on what activists and would-be activists gain from their cyberactivism. How may that (and other) collective action translate into social change? 
Castells (2015) sees social movements not just as products of social injustice. Though rooted in injustice, the birth of movements are triggered by emotions-primarily, fear and hope. Challenging injustice puts individuals at risk from those challenged. To undertake such an action, hence, the challengers need to overcome fear. This, in the networked society Castells describes, is done through the creation of online communities-which brings togetherness and solidarity, and also collective anger at the oppressors, providing the fundamental psychological structure that protestors need to counteract fear.

But overcoming fear is not enough. To enthuse individuals to take action, the emotion of hope is also needed. Protestors need to see the possibility that their risky challenge will bring about rewards. This, too, is provided by social networks, which allow for challengers to share experiences and be influenced by actors of change. Here, in a space largely free from the control of those in power, through communicative interactions, social movements are able to shape themselves as structures of 'counterpower', a first step in their challenge of institutionalised power. "The Big Bang of social movement," Castells writes (2015:13), "starts with the transformation of emotion into action."

Castells's notion of counterpower is relatable to the notion of counterpublic (Fraser 1990, Habermas 1999, Downey and Fenton 2003), which is also helpful in exploring the dynamics between social media and social change. Fraser (1990) uses the term to describe "parallel discursive arenas where members of subordinated social groups invent and circulate counter discourses". As several studies have evidenced (eg: Penny and Dadas 2014, Thorsen and Sreedharan 2019), such counterpublics align marginalised groups and push for their cause to be heard in the mainstream public sphere-breaking up "consensus structures within dominant publics [and] engaging with wider audiences" (Toepfl and Piwoni 2017: 4). In Castells's conceptualisation, this is the space in which "autonomous communication" required for the construction of counterpower occurs. Choi and Chi (2017), based on their study of counterpublic spheres in South Korea, see protestors networking on social media to provide each other a "sense of belonging" (the togetherness and solidarity that Castells describes) and share expressions of affection and mutual empowerment (the overcoming of fear and the achievement of hope, as per Castells). Further, individuals also conduct disputes and justify rationales for supporting the cause, and collaborate on planning and coordinating public actions.

Public action is crucial for correcting the injustice(s) that social movements seek to address. For Castells (2015) this needs to spill from the cyber into the physical world; 
actions of defiance must take place in conventional urban spaces to reclaim for citizens what has been lost to institutionalised powers. Defiance, in his view, is the application of the autonomy (and counterpower) protestors have acquired online. And without that, a movement cannot bring about true (sustainable) transformation. "Autonomy without defiance becomes withdrawal," Castells cautions. "Defiance without a permanent basis for autonomy ... is tantamount to discontinuous activism" (Castells 2015: 250).

The success of the last phase-of public defiance, the outright challenge to powerrequires more than the mobilisation of counterpublic(s). It also needs to have the ingrained capacity to build mass support-in other words, the ability to sway a significant section of the mainstream public. This exercise of winning over the public is quite likely to straddle the cyber and the physical-sections of the counterpublic may already be challenging sections of the mainstream with conversations or digital campaigns before collective 'physical' action occurs-and continue to do so through the life of the movement. It is conceivable then that the quality of success (or failure) of a social movement and that of the change it engenders-the extent to which its social goals are achieved, the speed of that achievement, and the sustainability of what was achieved-are dependent on the efficiency with which the protestors are able to connect with the hearts and minds of the masses. Thus, extending Castells's idea that emotionality is a key ingredient of transformation, we argue that the more emotive the connection that activists forge with the public through their collective action-be it through the idealism of their cause or specific strategies of persuasion they employthe more chances they have of achieving their goals. As Kamel (2014) put it, change emanates from people and passion, not the devices that link them.

\section{The \#MeToo of Indian journalism: networked and social}

\#MeToo was one of the most emotionally charged campaigns to consume the public consciousness of India in recent years. Joseph (2011: 196), writing in a different context, speaks of protestors proclaiming "in voices and actions heard around the world, that they are as mad as hell and they aren't going to take it anymore." This was very true of the Indian campaign.

\#MeToolndia, however, was distinct from its US counterpart in more than one respect. It was arguably more of a "networked social movement", purposefully organised and more structured in its support system for protestors-but also less impactful in evoking supportive responses from the institutionalised powers-that-be in India. For instance, where the national reckoning that the Harvey Weinstein case precipitated in the US led to criminal charges and changes in law and corporate practices quickly (Goel, Venkataraman and Schultz 2018), \#MeToolndia activists appear to be fighting a longer 
and harder battle to convince institutions and authorities about the experiences they have shared.

It is also important to note that the movement saw more journalistic involvement than elsewhere-not just as media professionals reporting on other cases, but in their personal capacity, as women who had been subjected to sexual indignities in their work environments. While the women who spoke out were predominantly the more 'privileged' members of the Indian society (BBC 2019), the significant number of journalists who came out to share their experiences of sexual harassment and assault is indicative of the dimensions of this problem.

To put this in context, the journalism industry in India is "plagued by deep-rooted misogynist attitudes and is largely perceived as an unsuitable profession for women" (Fardis 2017:2). The gender balance in Indian newsrooms is heavily skewed-only 25 per cent of the journalistic workforce is female (IWMF 2011), and news organisations and news processes are fashioned to the advantage of male journalists (Joseph 2005). Women are paid less, significantly less represented in managerial positions (IWMF 2011), and largely left out of 'power' beats such as political reporting (Joshi, Pahad and Maniar 2006; Priyadarshan 2013). This marginalisation is particularly pronounced outside city limits, in regional news organisations (Mullick 2015).

Not surprisingly, like in other spheres of the Indian society where rape is severely underreported (Bhattacharya and Kundu 2018), complaints about sexism and sexual harassment have been part of the 'normal' journalism environment. While there is a dearth of scholarship on this, many women have spoken out over the years (Philipose and Kesavan 2019), though, once again, this was mostly the more privileged English journalists and as individuals rather than a collective movement in pursuit of justice. Against this backdrop, we pose the following question.

RQ1: How prevalent is sexual harassment/violence in the work spaces of Indian journalists?

\#MeToolndia, as mentioned earlier, was also unique in the way it utilised social networking to shape disparate and spontaneous interactions, very quickly, into a counterpublic, and a movement. While the story 'broke' in a television interview where former Bollywood actor Tanushree Dutta recalled an earlier complaint of sexual harassment she had made against film star Nana Patekar, it took a life of its own on Twitter. Sandhya Menon's naming of colleagues who had sexually harassed her, and her public appeal on Twitter for others to share their experiences saw an outpouring of allegations, angst, and anger-emotions that drive action, according to Castells 
(2015)— that engaged with the 'main' public sphere, challenging dominant views (Mullick 2015) and connecting and converting select segments to their cause. As Jayaram (2019) writes, in the US the fourth estate "not only broke the news, but also provided the still-continuing, multi-layered follow-up. In India, the opposite transpired. Twitter gave us the breakthrough and then social media and mainstream press got together to give readers the \#MeToo India stories."

Two critical points must be noted in this context. First, while the birth of \#MeToolndia was grounded in social media, there were several other factors that led up to it. In a panel discussion at the start of the movement, Menon put it thus: "I think it has been long coming." The groundwork for this \#MeToo moment, according to Kirby (2018), started with the 2012 New Delhi gang-rape, which incited "real activism and discussion about violence against women and other gender equities". The success of the protests that the 2012 event spurred - the criminal convictions and the legal changes that came after, including the Sexual Harassment of Women at Workplace (Prevention, Prohibition and Redressal) Act, 2013-also provided a more robust legal structure for activists in their fight against rape culture. So did, possibly, the 2017 call of \#MeToo and the resultant fall of several Hollywood elite. All of these, most importantly, provided activists the confidence — the hope, as Castells (2015) would put it—-that such issues can be challenged in public, and with success.

Secondly, the great deal of discourse that was evident on Twitter was only the tip of the iceberg. Beneath that was a sea of networked communication. As activists involved in \#MeToolndia have said, women have been sharing information about "creeps" on closed networks, providing warnings and solidarity for each other for years. Such personal networking — particularly on WhatsApp and via direct messages on Twitterplayed a particularly important role before perpetrators were 'called out' in the movement. Activists have revealed they used personal messaging and networked within closed groups to vet and remediate allegations before public 'outings'. These networks can thus be seen as part of the \#MeTooIndia counterpublic sphere, and were used to coordinate with the many affiliate and advocacy networks the movement succeeded in galvanising (eg: legal support).

Though the movement addressed sexual misconducts raised by women from different walks of life, its activities were largely centred around journalism and journalist-activists, in part because many of the stories came from women journalists and were about senior journalists. Several of those who emerged as leaders and public faces-for instance, those in the coalition that had formed to support the women coming forward after Menon's public call—were also journalists, and Akbar, the most high-profile person 
against whom a significant number of women had levelled allegations, was a former editor-in-chief.

The movement was criticised by many journalists for being binary and 'anti-men', with counter-campaigns and challenges emerging both on Twitter and in the physical world. It was also seen to be 'elitist', led by English journalists and failing to share the realities of women in regional newsrooms. But despite such criticisms, there was also a sense that the movement was much-needed and it would bring about much-welcome newsroom changes. In fact, more than one commentator had described it as the watershed moment for Indian journalism, and some of the cases generated notable news coverage. It is in this context that we ask the following.

RQ2: What perceptions do national and regional journalists hold of \#MeToolndia?

RQ3: How do Indian journalists describe the impact \#MeToolndia has had on their professional practices and work environment?

\section{Method}

We draw on 190 semi-structured interviews with national and regional journalists to answer our research questions. These interviews are part of a larger dataset of 250 interviews, which we conducted between September 2018 and July 2019, for the Media Action Against Rape research project.

The 190 interviewees were drawn from the six administrative zones of India-North, North-East, East, Central, West and South-and include journalists working in 14 languages. Our study includes both female and male journalists, at a balance of $45 \%$ and $55 \%$ respectively, and we included respondents from print, television, radio and online news media (see Table 1 below).

The 14 languages we drew our interviewees from include Hindi and English, the main languages of India, and 10 of the other most-spoken languages: Bengali, Marathi, Telugu, Tamil, Gujarati, Urdu, Kannada, Odia, Malayalam, and Punjabi. We also included Assamese, which belong to the state of Assam in the North-East, and Kashmiri, from the state of Jammu and Kashmir in the North. Both regions suffer from insurgency, with a heavy presence of security forces and restrictions on news media. This allowed us to cover two conflict areas, where the journalism environment is considered different, and which rarely feature in comparative research owing to difficulties of access. 
Hindi, which is the national language and mother tongue to more than 528 million people, is the largest in our sample, while Kashmiri, which has slightly less than 6.8 million speakers, is the smallest. English, the lingua franca that cuts across India's many states and regions, has only around 226,500 speakers-but is considered more influential than the numbers indicate due to its reach into the political and bureaucratic elite.

Table 1

\begin{tabular}{|l|c|c|c|c|c|}
\hline Region & Print & Television & Radio & Online & TOTALS \\
\hline North & 21 & 8 & 4 & 12 & 45 \\
\hline North-East & 3 & 3 & 0 & 1 & 7 \\
\hline East & 7 & 6 & 1 & 2 & 16 \\
\hline Central & 4 & 4 & 0 & 0 & 8 \\
\hline West & 23 & 6 & 0 & 3 & 32 \\
\hline South & 44 & 24 & 8 & 6 & 82 \\
\hline & 102 & 51 & 13 & 24 & 190 \\
\hline
\end{tabular}

Data for our analysis is drawn from two segments of the questionnaire administered in the 190 interviews. To answer RQ1, we draw on the first segment, which dealt with the journalists' personal experience or knowledge of sexual harassment or gendered violence in their work environment. To answer RQ2 and RQ3, we use data from the second segment, which included questions on the \#MeToolndia movement. Here, it is important to note that only 141 of the 190 interviewees were queried on \#MeToolndia, as the movement had begun after the start of our fieldwork for the MAAR project.

Interviews were conducted in the preferred language of the journalist, translated into English and transcribed by a native speaker of the language interviewed in. All transcripts were anonymised, and information that could identify the journalist removed before we began our analysis.

Data analysis was done using NVivo. We conducted a thematic content analysis, coding for the following: \#MeToolndia coverage by own organisation, Personal experience of sexual harassment or sexual violence in the journalism environment (either in the newsroom or in the field), Knowledge of sexual harassment or sexual violence (either in the newsroom or in the field), Perception of \#MeToolndia, and Perception of change from \#MeToolndia. The last two themes were further coded to assess the nature of the recorded perception and change. 
The coding was carried out by two coders (the first and third authors), who achieved an inter-coder reliability of Kappa $=0.82$. To record this figure, we went through three rounds of preliminary coding, with the second author moderating disagreements, before the coding manual was finalised.

\section{Experience or knowledge of sexual harassment in journalism environment} \#MeToolndia provided a platform for many journalists to speak about the sexual harassment and sexual violence they had suffered in their professional life. However, as noted earlier, the movement received criticism from interviewees for centring around journalism in cosmopolitan areas_-particularly, the English news media. This echoes previous scholarship that shows women have spoken out against harassment episodically over the years (Philipose and Kesavan 2019).

As our study focused on the everyday lived realities of journalists across India, from 12 vernacular languages as well as English and Hindi, it reveals different regional perspectives on challenges relating to sexual harassment and rape. It also demonstrates some commonalities that cut across, irrespective of language or news media type.

Overall we found $28 \%$ of journalists interviewed had direct personal experience of sexual harassment or sexual violence in their news environment. In total, 39\% reported to either have witnessed or have firsthand knowledge of journalists suffering such situations in their newsroom or the field. For this, we coded only references to firsthand knowledge, not hearsay or cases that had been reported in the media. Given that our sample was marginally skewed towards male respondents, we have broken down respondents by gender to unpack the extent to which these experiences follow a gendered dynamic (as could be expected), and to enable comparisons with other studies (some of which focus only on female respondents).

Immediately we find a stark contrast, with $58 \%$ of women journalists interviewed having personal experience of sexual harassment or assault. In terms of firsthand knowledge, we found a more balanced view: $49 \%$ and $31 \%$ of women and men, respectively. Some respondents did report direct experience, though they did not describe knowledge about others. This may reflect a sense of urgency to discuss their own traumatic experience at the expense of broader challenges, or a genuine lack of knowledge about other cases.

We found significant regional variations in terms of direct experience, which was more prevalent in the North (51\% of women journalists) and Central (38\% of women journalists). This can be partly explained by the North region covering New Delhi - 
which had seen a high level of protests after the 2012 gang-rape incident, and also much activism after a woman journalist accused Tarun Tejpal, then editor-in-chief of Tehelka magazine, of sexual assault-had offered female respondents a better environment to speak out.

None of the respondents in the North-East reported personal experience, although this likely reflects the small number of respondents from this region, rather than an absence of the problem. Indeed, this is corroborated by a number of interviewees, who described firsthand knowledge of cases.

Working conditions appeared to be better in radio compared with online, television and print newsrooms. Some $38 \%$ of online journalists, $27 \%$ in television, and $25 \%$ in print reported personal experience of sexual harassment or assault-either in the newsroom or in the field (see Figure 1 below) — compared with only $8 \%$ in radio. This was also borne out by the interview data, in discussions of how newsroom cultures differ across mediums. One female print journalist from Hyderabad noted:

"In electronic media girls are facing some problems... harassment. But in print, according to me, nothing has happened. But in some electronic media, yes. It is there. Girls are still struggling to establish themselves."

Figure 1

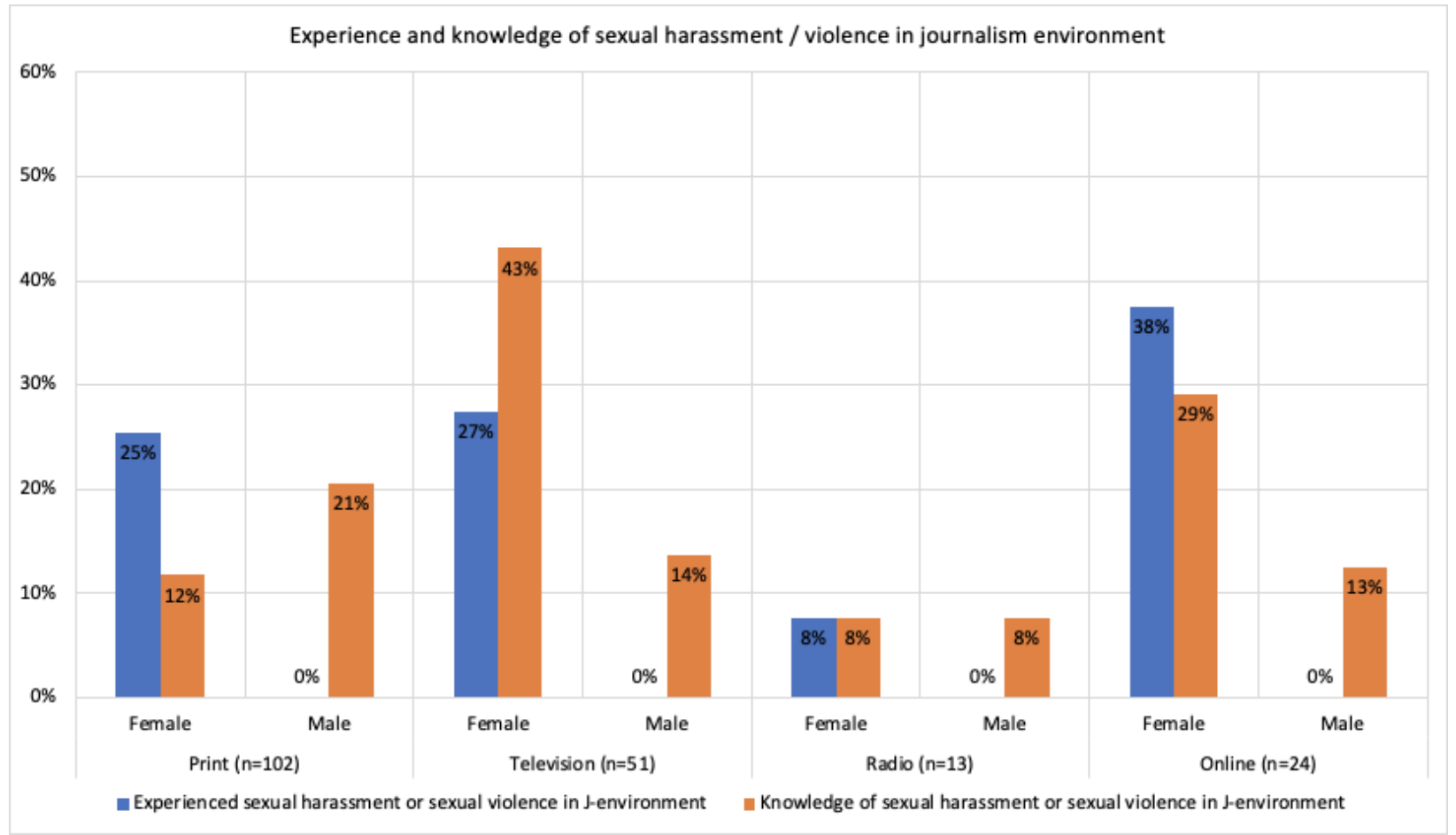


Across the whole sample we found a significant proportion of journalists who not only had direct personal experience, but also witnessed or was aware firsthand of others who had been harassed or assaulted. This provides substance to claims made in the \#MeToolndia campaign, and challenges assumptions that reports flourishing at the time about sexual harassment was merely hearsay, or people referencing the same incidents second- or third-hand, or, indeed, reflecting on what they had seen in news or social media.

We found that firsthand knowledge was most prevalent in television news, although the readiness to describe this was highly gendered (43\% of female journalists and $14 \%$ of male). This pattern was also echoed in online newsrooms (29\% of female journalists and $13 \%$ male). However, this was the reverse in print media, where more male journalists reported firsthand knowledge than women (12\% of female journalists and $21 \%$ male).

Sexual harassment and abuse in the newsroom

In exploring the nature of sexual harassment or assault that journalists experienced or had knowledge of, we distinguished between cases that took place in the newsroom (or office space) and those that took place in the field (ie, during newsgathering or other work trips). Direct experience of sexual harassment and violence within the newsroom or office space typically involved a senior colleague or supervisor, a person with power through seniority or line management responsibility. A number of journalists described in detail different levels of physical abuse, ranging from sexual assault and molestation, to unwanted touches, kisses or advances. One female journalist described how she "was assaulted by my own editor", adding the work environment for women in journalism was "pretty unsafe". Noting how she relied on family for support through the ordeal, she said, "It was indescribably hard to report at that point of time."

The journalist also mentioned that in her case, after she reported the incident, there were many who took the side of the editor. This was a common pattern we found with those describing personal experiences, that their exposure of the perpetrator did not yield uniform support, but instead divided people as supportive of either the victim or the accused - the latter imbued by either lack of trust in the claims being made, a refusal to recognise the acts as problematic, or a desire to not upset the working relationships.

Non-physical harassment was even more prevalent, with journalists describing a range of unwanted behaviour. This includes male colleagues commenting on appearance or behaviour of female journalists, with demeaning or sexualised connotations. Some journalists described isolated incidents, whilst others said they experienced prolonged 
patterns of systematic abuse and coercive behaviour by superiors. A New Delhi-based female journalist from a Hindi publication provided an example:

"My editor, he started stalking me and started sending messages, calling me, saying all kinds of things, making me sit in the cabin the entire day and saying things about my body and making very sexist remarks."

Despite such behaviour being clearly unwanted, interviewees often described how the journalism work culture had normalised these interactions - to the point they became routinised expectations of the everyday lived reality of female journalists. Consequently, we found that in our interviews, women often described harassment 'accidentally', not consciously thinking of these as problematic. This was a theme that arose during the \#MeToolndia movement as well-prompted by revelations of others, journalists would reflect on experiences that had happened to them, recognising in hindsight that they too had been subjected to similar behaviour. This is relatable to some as subtleties of harassment, in which the patriarchal routinisation of newswork had made women journalists question their own judgement about what they were subjected to. A New Delhi-based female online journalist spoke about this:

"Yeah it happens all the time. People are always passing comments on you, it happens in a more subtle way inside the newsroom. A lot of times you only realise that it was harassment much later, not when it happens. You just tend to pass it off as maybe they are just trying to be funny or something."

Here it is important to note that because the articulation of having been sexually harassed - their delayed understanding of having been victims -is a self-reflexive development, it does not mean the incident(s) did not impact them at the time. Journalists said they had suffered because of the environment, even if they had not noted individual incidents of being wronged.

Indeed, we found evidence to support journalists experienced mental distress—both as a consequence of physical abuse, and as a consequence of other forms of coercive behaviour. The latter sometimes created a hostile environment where journalists would have mental breakdowns or suffer traumatic stress. Some female journalists would go to significant lengths to avoid advances or potential abuse from people in the workplace, which sometimes caused them to change their patterns of behaviour in their private lives as well. One female print journalist in Assam described how she arranged to be picked up from work by male friends out of fear of her superior. The harassment was so intense she suffered from depression and constant fear of being raped: 
"I felt so harassed mentally, I would break down in office because he would shout at me in front of everyone. I got so depressed that I felt that when I was staying late at office, he may rape me. Oh god! I felt so scared that he would molest me or rape me."

Whilst our study focussed on journalists currently working in the news industry, we know from experiences shared through the \#MeToolndia movement that many journalists left the profession as a direct consequence of harassment or assault. Our interviews also revealed some examples of this, where respondents described moving from one news organisation to another, or spoke about friends who had quit the profession entirely. There was evidence of this in both urban and regional newsrooms.

Some interviewees described regional newsroom challenges as greater than in urban newsrooms-ranging from sexual harassment to professional marginalisation due to patriarchal cultures. A female Hindi television reporter in Lucknow described quitting one news media for another, and also resisting pressure from her family to work in regional rather than urban newsroom:

"I know that the condition of the English media is not good currently but when it comes to the regional media, it's even worse. In English media also they don't think women to be capable enough but here they will put women down completely. And I never wanted to be just like a doll sitting there, who knows nothing and the entire context is ready made, written by other people."

She also described knowing about a number of instances of sexual harassment, including one colleague who "quit journalism altogether". During the \#MeToolndia movement the colleague spoke to her on Facebook about a "celebrated male reporter" they had both worked together, and who was known to have harassed not just her former colleague, but many others as well.

Other journalists described being abused or harassed even after they resigned because of toxic working conditions. They also spoke of the lack of repercussions for male journalists, who continued to work in the same place, thus contributing to a hostile environment by their very presence. A Mumbai-based male reporter from the print media described this as follows:

"Let's not take names but I know a couple of fellow reporters-no female journalist would talk to them today. Female reporters are not comfortable being in the same space as them. And these are people I thought I knew, and then the reports I got about them are shocking." (Male print reporter, Mumbai) 
This lack of consequence for perpetrators was of course a common theme in the \#MeToolndia campaign, both in online debates and panels that were organised to debate the issue.

\section{Safety of journalists in the field}

Besides sexual harassment and violence within newsrooms, we also explored the experiences of journalists in the field -that is, the working conditions outside their newsrooms. Newswork naturally involves engaging with sources, and those points of interaction could expose vulnerabilities to the reporters' safety. Sexual harassment in the field was often described as more prevalent than in newsroom, an almost expected condition of working as a journalist:

"In the field, I have lost count. It happens so many times in a day when you are on the field, let alone in my career so far. In the organisation, touchwood, nothing as such. Field reporter, too many times." (Female print journalist, Chandigarh)

"In newsroom, nothing like that. Outside on the field, of course." (Female print journalist, Chennai)

We identified three areas where female journalists are particularly vulnerable during newsgathering. Firstly, incidental abuse by passers-by, often "drunken guys", who would shout demeaning or sexualised comments at reporters. Here it is unclear if the act of harassment is targeting the journalist because of their profession, or because of their gender. One female television reporter from the state of Karnataka described both scenarios:

"When I am on the field, the drunken guys will irritate us, wherever we go. Or boys on two-wheelers or bikes, they will shout on us. They will put some kind of vulgar words towards us."

Secondly, journalists described their interactions with police officers as a potential event for harassment, but one unavoidable when pursuing crime stories. "A criminal has never made me feel as uncomfortable as a police officer makes you feel," noted a female Gujurati print journalist. The journalist, as also several other journalists, described changing their behaviour and dress code when working in these spaces.

Police stations were also described as potentially unsafe for people who were arrested. A male print journalist in Tamil Nadu, for example, described the arrest of a teenager on suspicion of stealing a mobile phone and how "the police themselves sexually harassed 
him, around 3 to 4 men". Whilst incidents such as these did not directly involve the reporter (indeed the male journalist described doing a subsequent sting to uncover the abuse), they reinforced that there is indeed an environment that is hostile.

The third area of challenge for female journalists in the field related to dealing with elite sources, such as politicians, public officials, senior civil servants, and celebrities-fairly routine interactions for many journalists. Here journalists described some sources as behaving unprofessionally, at times making advances, with a sense of entitlementeither by talking or acting in a derogatory manner towards them. This included both people who themselves held senior positions, as well as those who had connections with people in senior positions. A New Delhi-based online journalist described an encounter as follows:

"Yeah, and this was a very senior bureaucrat. People with high, like, political connections. I ignored it the first time, I thought I heard it [wrong]. That's what women do right, but he said it again so that I hear it."

For women journalists, this creates a duality of professional pressures. In the newsroom, they potentially jeopardise their career progression (or even employment) by rejecting the advances of their superiors. And in the field, by rejecting those made by their sources, they may miss out on key aspects of stories, which in turn may affect their career progression or job security. These pressures, we argue, have historically meant a degree of self-censorship from women about the conditions they endure, both in the workplace and the field.

We now turn to the question of how our interviewees perceived \#MeToolndia, and the extent to which they felt it had contributed to changes to the journalism industry.

\section{Perception of \#MeToolndia}

Analysing responses expressed about the \#MeToolndia movement (RQ2), we find a mixed picture. Expectedly, journalists were not unequivocally supportive of the campaign; only $36 \%$ of female journalists and $22 \%$ of male journalists expressed support for the movement without any reservations. A further $19 \%$ and $23 \%$, respectively, had mixed views about the campaign (see Figure 2 below).

What is striking is the large proportion of journalists who were critical of \#MeToolndiasome $23 \%$ of female journalists and $22 \%$ of male journalists respectively. In terms of regional distribution, we found female journalists in the West and North regions were most supportive ( $28 \%$ and $25 \%$ respectively). Male journalists were more critical than 
either supportive or mixed in all regions, apart from the South, where only $6 \%$ of male journalists were critical.

More striking, however, is the number of female journalists who were critical of the campaign. This was particularly prominent in the North, where $18 \%$ of women criticised the movement. When extrapolating this by languages, we find that English-speaking journalists were both the most supportive and the most critical (likely a reflection of the split in cosmopolitan newsrooms on the issue), whilst Tamil, Bengali and Telugu journalists were more likely to express criticism.

Figure 2

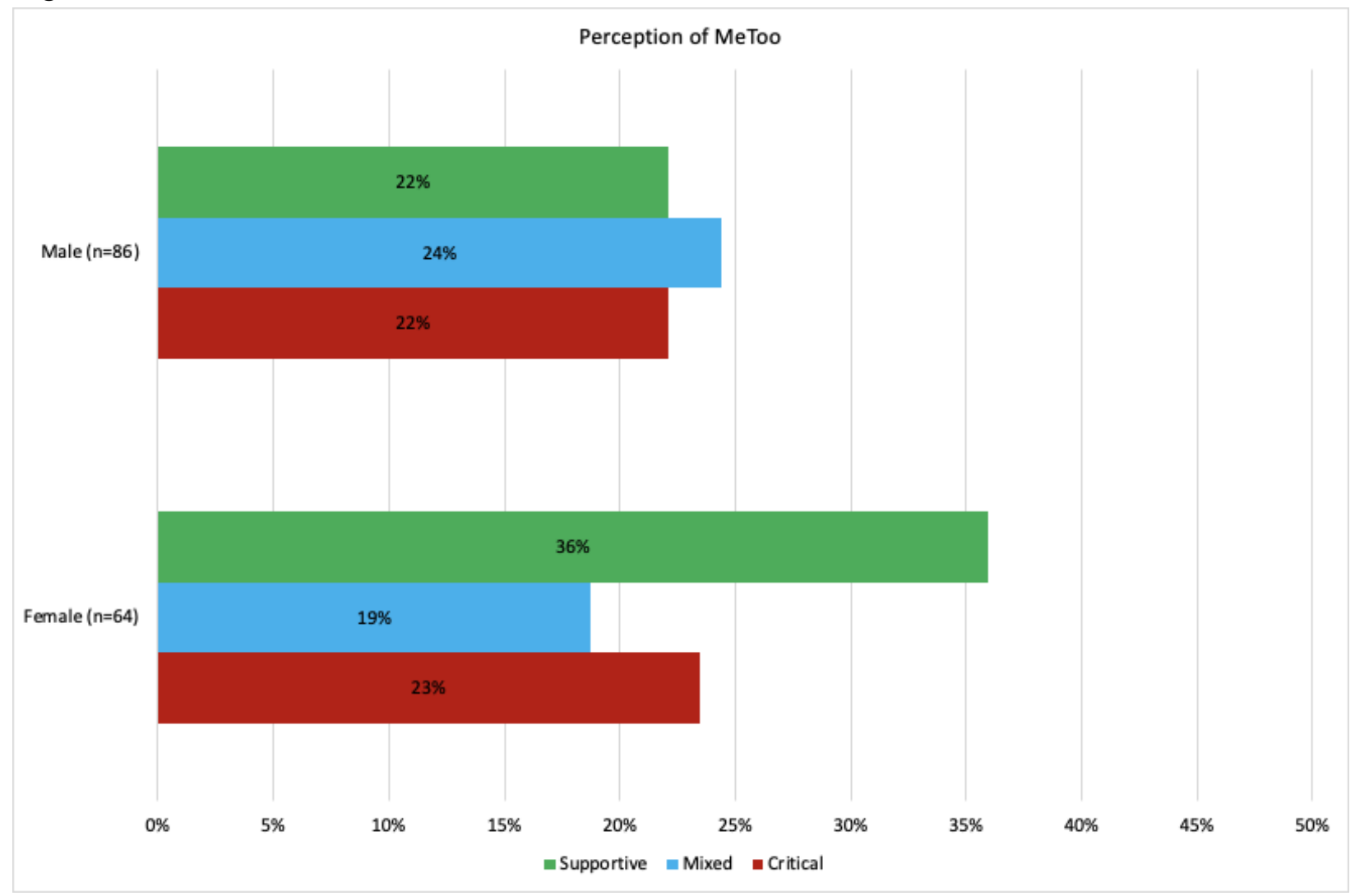

\section{Criticisms of \#MeToolndia}

We identified three main strands of criticism. Firstly, there were those who questioned the lateness of the accusations women were raising on Twitter. Some journalistsespecially male_complained they didn't "understand people [only] started complaining" now (male print journalist, Madurai). Others were similarly critical, even though they noted the original \#MeToo movement may have had its merits. Here the perception about its inflection in India was negative, again because of victims' failure to speak out sooner and the lack of convictions that followed: 
"I have always said that wherever this movement started it did well, but its version in India tarnished the original campaign. Most of them who were accused have not been convicted. Why did they not speak earlier?" (Male print journalist, Kashmir)

"I think that it has a revenge motive behind it. Because if they wanted to complain they could have done it a while ago, right?" (Female television journalist, Trichy)

The second strand followed a similar direction, questioning the validity of the revelations that emerged. Here we found both accusations that those stepping forward were not real victims, and accusations that the \#MeToolndia campaign was being misused to further other interests. One female television reporter in Bangalore said "this is all stunt mania", and that things only happened with two willing participants. This was echoed by a female print journalist in New Delhi, who said:

"What happened in the case of Akbar is an exception. I think many women have willingly gone with this kind of man. It's a considered surrender."

One male online journalist from Kashmir, for his part, said a colleague from New Delhi had "tried to be a victim" in order to "settle scores with a male journalist". Others expressed that the misuse of the campaign was a concerted effort, with one male journalist from Kottayam in Kerala describing how in his view "some women with support from political parties and all are misusing it". Where evidence emerged of highprofile individuals exhibited predatory behaviour, the critical interviewees dismissed as exceptions.

The third theme to emerge from the critics related to the perceived cosmopolitan nature of \#MeToolndia. This included a sense that \#MeToolndia "was made into a movement of the English media only" (male print journalist, Lucknow), and that "those who are getting entangled in MeToo belong to blueblood" (male print journalist, Kolkatta). Engulfed in this was both the sense of exclusion that many regional and vernacular journalists seem to feel, as well as the sentiment that the movement failed to reflect the diversity of the Indian media. A female print journalist from Chandigarh spoke of this:

"A lot of the media's attention has been, again, on survivors with a certain caste and class profile. There is much less space to listen to violence against the Adivasi women, or, you know, rural women."

These critical themes reflected dissatisfaction with how the movement was operationalised, rather than its premise of gender equality or safety for journalists. Indeed, no respondent expressed the view that suggested they felt sexual harassment 
or abusive behaviour was justified. Instead, their criticisms were about the organisation and composition of the movement, and the content disseminated on social media by activists.

\section{Supportive of \#MeToolndia}

The most important factor for interviewees to express support for \#MeToolndia was the sense that it provided a platform for women to expose the abuse they faced at their workplace, to discuss boundaries, and share support information. Most of all, interviewees expressed that it was a long-overdue acknowledgement of the social problem of objectifying women:

"It doesn't matter whether it happened years ago, or happened in the recent past. It is a chance to talk. To find courage. To bring out gender inequality. It is a step towards men acknowledging that their view on women as just sexual objects should change." (Female print journalist, Bangalore)

"What I feel, MeToo was not a legal movement, it was a social movement. Women came out from their shells and said that this happened with me. (Female television reporter, New Delhi)

Secondly, many journalists expressed a sense of satisfaction that the power balance between men and women had shifted as a consequence of \#MeToolndia. As a female print journalist from Mumbai put it: "It's a good thing men are finally scared."

This sentiment was not isolated to female journalists. Men, too, seem to recognise that the public nature of exposure engendered by social media outings would have a positive effect. A Trichy-based male print journalist said:

"Men usually have the confidence that women won't speak out against them. But if they do so on social media, men know that they will be recognised, humiliated. This fear will help control issues like these."

Whilst some interviewees did express concern about the campaign's impact, especially outside English-language newsrooms, there was a general sense that there were more advantages than disadvantages from the movement.

\section{Perception of change after \#MeToolndia}

Our final line of enquiry was the extent to which journalists felt the movement had made any tangible changes to their work environments (RQ3). Whilst there was a degree of uncertainty around this question (some $22-23 \%$ of both female and male journalists said 
they were unsure of impact), there was a distinct emphasis on no change or even negative change ( $47 \%$ of men and women overall). There were no major gender differences in this, with female journalists being marginally more positive overall in terms of perceiving changes to have emerged from \#MeToolndia. There was a degree of polarisation here, however, as they were also fractionally more likely than men to perceive \#MeToolndia as having had a negative impact.

Figure 3

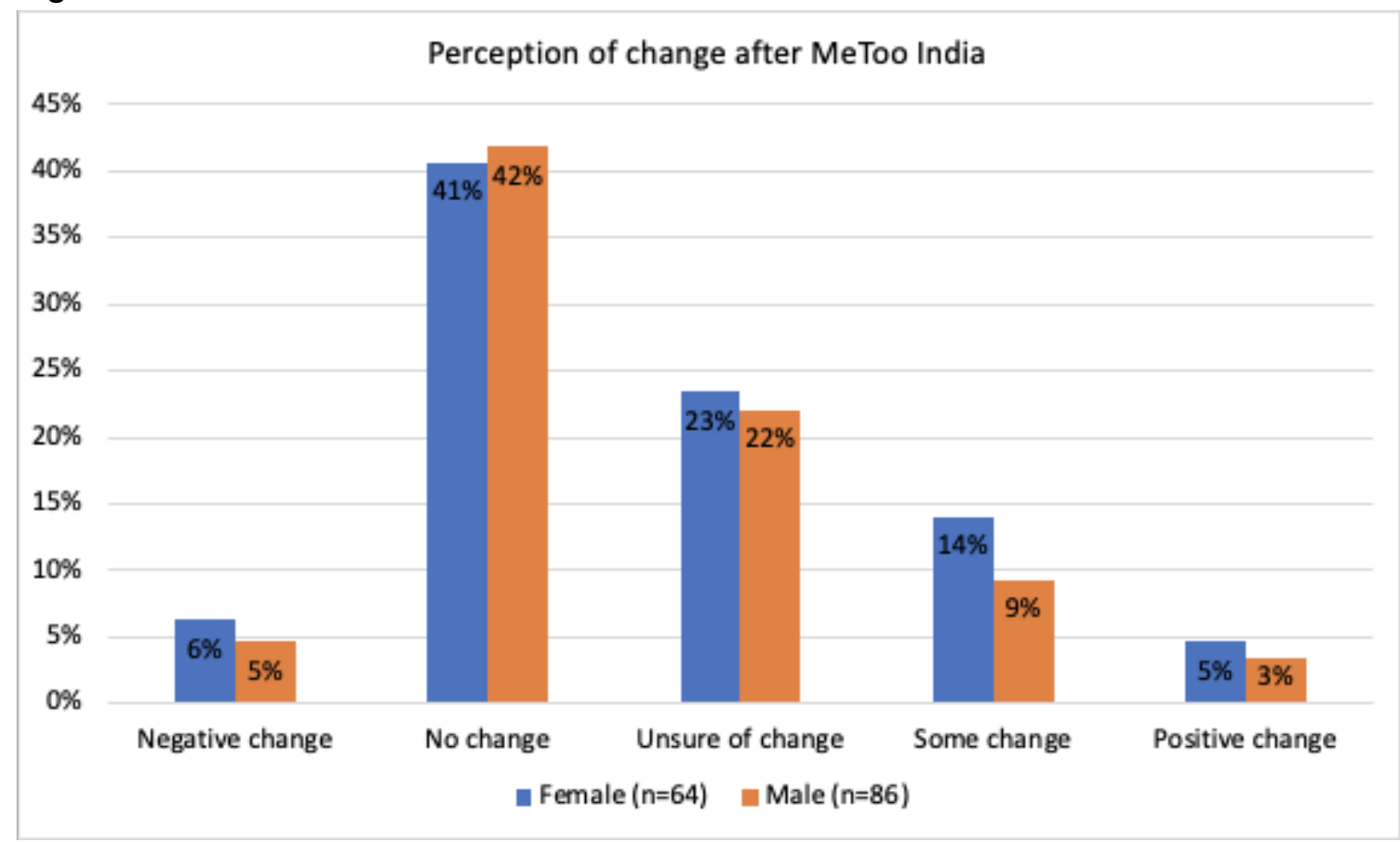

In this perception, we did however find that there was a significant difference between national and regional newsrooms-journalists working in regional newsrooms were much more likely to claim there had been no changes as a consequence of \#MeToolndia. This echoes findings from the previous section that indicated the movement was perceived as English-centric and belonging to the cosmopolitan elite.

Media type was also a factor here, with online journalists significantly more positive about changes after \#MeToolndia than print or television journalists. Radio interviewees were polarised, with men reporting positive change and women reporting no change. 
Exploring these responses thematically, we identified four groups. Firstly, there were those who acknowledged the campaign had made an impact on the news contentinsofar that the \#MeToolndia movement itself became a news story-but that in terms of changes in the newsroom "there hasn't been much of a difference except that we reported on cases" (female print journalist, Ahmedabad). Secondly, there were those who expressed there had been no change, because "our field doesn't see any much harassment" (male television journalist, Chennai). In these responses journalists would reject even the idea of investigative procedures, claiming there was no need because there was no problem (and using anecdotal claims of "no complaints" as evidence).

Thirdly, there were those who said there had been some momentary change, followed by realignment with previous norms. This included journalists who described examples of cases that had been investigated, without further action being taken and the journalist being reinstated. Many others recognised it had triggered a heated debate, but felt there had been no material change in journalism practice or newsroom cultures:

The \#metoo movement came, and then it went away, that's what I feel. Nothing happened with the \#metoo movement, what happened, you tell me, you faced it, so many girls put all their problems on Facebook or Twitter, but no complaints or cases or judgments were made. (Female television journalist, Bangalore)

Fourthly, and connected with the previous theme, was those who claimed any changes were confined to the cosmopolitan or English language newsrooms. "This movement might have helped the people in the elite class of the media," said one male television journalist from Lucknow, "but not here."

We found similar themes in cases where interviewees said the \#MeToolndia brought about some changes as well. Chiefly, this was a perception that the movement had precipitated a positive change in the news environment. Specifically this was connected with the provision of a platform for articulating dissent against patriarchal norms and values, as well as exposing harassment and assaults.

One male print journalist from New Delhi described the "enthusiasm among my female colleagues" and "as the news broke there was so much energy", which was spurred by the \#MeToolndia revelations. "It was very good to see," he concluded. Others acknowledged "the main channel is very urban and elite", but feeling like "\#MeToo has had enough resilience and is loud enough to have made it to regional newspapers" (female online journalist, New Delhi). However, the same person also conceded that the debates on Twitter engaged only a small proportion of people who were online, which in turn was also underrepresented. 


\section{Conclusion}

We investigated three aspects of \#MeToolndia, conceptualising it as a 'networked social movement' (Castells 2015) that strived to change the culture of sexual harassment and sexual violence women faced in workplaces. In particular, we focussed on the journalism industry.

First, we looked at the prevalence of sexual misconduct in the news environment (RQ1), considering it the ostensible cause and injustice that triggered the movement. Studies in other national contexts (see Franks 2013) indicate around 60\% of women journalists suffer some sort of sexual harassment at the workplace. Our findings align with this. We however found a more complex set of dynamics, given the regional and cultural diversity of our respondents.

Overall $58 \%$ of women journalists reported they had personal experience of sexual harassment or violence at work. Further, $49 \%$ women and 31\% men reported firsthand knowledge of such misconducts. There were significant regional variations in terms of direct experience, we found, with women journalists in the North (51\%) and Central (38\%) zones reporting more direct experiences. Sexual misconducts were prevalent across all media platforms, though female journalists working in television and online spoke of such incidents more than those in print and radio.

Secondly, we sought to understand how \#MeToolndia was perceived by journalists (RQ2). Not surprisingly, we found mixed reactions here: $36 \%$ of female and $22 \%$ male journalists supported the movement unequivocally, whereas $19 \%$ and $23 \%$, respectively, had reservations. Interestingly, a significant number of women-23\%were critical of the campaign, with much of that criticism coming from the North. Women from English publications, we found, were both the most supportive as well as most critical of the movement, faulting it mainly for the way it was operationalised, including the lateness of raising accusations, validity of claims, and the marginalisation of regional journalists.

The third aspect we explored (RQ3) was the tangible changes the collective action of \#MeToolndia engendered. While $23 \%$ of respondents expressed themselves as unsure of changes, there was a distinct emphasis among the rest that the movement did not succeed in achieving its social goals. Most (47\%) said it brought no meaningful change to either their newswork or newsrooms—and even that it had been "negative'. In this belief, there was no major gender difference (female journalists were marginally more positive). There was, however, a significant difference between regional and national 
journalists: the first group was much more likely to say-often vehemently - that \#MeToolndia had not impacted their work spaces.

Three points can be made to place these findings in context. The significant prevalence of sexual harassment or violence at work reported by journalists, both men and women, across all zones and media platforms, lends credence to the \#MeToolndia activists belief the movement was long overdue and justifies their sense of social wronging. Though seen as an 'elite' movement, there is evidence that the injustice it seeks to address is neither a 'New Delhi' phenomenon nor limited to English news media. Importantly, it is possible the numbers reported here are the lower end of the spectrum-in a country where sexual violence is severely underreported, it falls to logic that the affected, even empowered journalists, might not always speak out for more than one reason.

It must be noted that while there was much criticism about the \#MeToolndia movement, these were limited to its operationalisation. There was consensus among journalists the cause was "good". Also, for many journalists, particularly in vernacular newsrooms, such problems did not exist "here", in their newsrooms. Whether this reflected the nature of that newsroom, or was an attempt to 'close ranks'-either institutionally or in terms of gender-needs further exploration.

Finally, we wish to highlight three (possibly) interconnected perceptions that a crosssection of respondents alluded to: one, the campaign is men vs women; two, it marginalised women in regional spaces; and three, it has "come" and then gone" and nothing has changed. These are sentiments that \#MeToolndia activists need to address for the successful pursuance of their campaign.

\section{Acknowledgements}

The authors thank UNESCO, New Delhi, and our research assistants in India who worked very hard to help us put together the extensive, multilingual dataset on which this study is based.

\section{References}

Bellin, E. (2012). "Reconsidering the Robustness of Authoritarianism in the Middle East: Lessons from the Arab Spring." Comparative Politics 44 (2): 127-49.

Benford, R. D., \& Snow, D. A. (2000). Framing processes and social movements: An overview and assessment. Annual Review of Sociology, 26(1), 611-639 
Bhattacharya, P. and Kundu, T. (2019). 99\% cases of sexual assaults go unreported, govt data shows. [online] https://www.livemint.com. Available at:

https://www.livemint.com/Politics/AV3sIKoEBAGZozALMX8THK/99-cases-of-sexualassaults-go-unreported-govt-data-shows.html

Bhattacharya, P. and Kundu, T. (2019). 99\% cases of sexual assaults go unreported, govt data shows. [online] https://www.livemint.com. Available at:

https://www.livemint.com/Politics/AV3sIKoEBAGZozALMX8THK/99-cases-of-sexualassaults-go-unreported-govt-data-shows.html

Bruns, A., Highfield, T. and Burgess, J. (2013). 'The Arab Spring and Social Media Audiences', American Behavioral Scientist, 57(7), pp. 871-898. doi:

$10.1177 / 0002764213479374$.

Chattopadhyay, S. (2019). The women left behind by \#MeToo in India. [online] BBC News. Available at: https://www.bbc.co.uk/news/world-asia-india-47025662

Choi, S. Y. and Cho, Y. (2017) 'Generating Counter-Public Spheres Through Social Media: Two Social Movements in Neoliberalised South Korea', Javnost - The Public, 24(1), pp. 15-33. doi: 10.1080/13183222.2017.1267155.

Christensen, H. S. (2011). Political activities on the Internet: Slacktivism or political participation by other means?. First Monday, 16(2).

http://dx.doi.org/10.5210/fm.v16i2.3336

Earl J and Kimport K (2011) Digitally Enabled Social Change: Activism in the Internet Age. Cambridge, MA: The MIT Press

Fenton, N., \& Downey, J. (2003). Counter public spheres and global modernity. Javnost/The Public, 10(1), 15-32.

Fraser, N. (1990). Rethinking the public sphere: A contribution to the critique of actually existing democracy. In C. Calhoun (Ed.), Habermas and the public sphere (pp. 109142). Boston: MIT Press

Freelon, D., Mcllwain, C. and Clark, M. (2018) 'Quantifying the power and consequences of social media protest', New Media \& Society, 20(3), pp. 990-1011. doi: 10.1177/1461444816676646. 
Gerbaudo, P. and Treré, E. (2012) 'In search of the "we" of social media activism: introduction to the special issue on social media and protest identities', Information, Communication \& Society, 18(8), pp. 865-871. doi: 10.1080/1369118X.2015.1043319.

Gladwell, M. (2010) "Small Change." The New Yorker, October 4. http://www.newyorker.com/ reporting/2010/10/04/101004fa_fact_gladwell?currentPage=all.

Global report on the status of women in the news media. (2011). Washington: International Women's Media Foundation (IWMF).

Goel, V., Venkataraman, A. and Schultz, K. (2018) \#MeToo Movement Suddenly Takes Off, https://www.nytimes.com. Available at: https://www.nytimes.com/2018/10/09/world/asia/india-sexual-harassment-me-toobollywood.html. (Fardis 2017:2)

Habermas, J. (1989). The structural transformation of the public sphere. Boston: MIT Press

He, B., and M. E. Warren. 2011. 'Authoritarian Deliberation: The Deliberative Turn in Chinese Political Development.' Perspectives on Politics 9 (2): 269-89.

Jayaram, R. (2019) How the news cycle killed \# MeToo in India, newslaundry.com.

Joseph, A. (2005). Making News: Women in Journalism. New Delhi: Penguin Books India.

Kirby, J. (2019). The rise of \#MeToo in India. [online] Vox. Available at: https://www.vox.com/2018/10/24/17989650/me-too-india-akbar

Castells, M., 2015. Networks of Outrage and Hope: Social Movements in the Internet Age.

Morozov, E. (2012). The net delusion. New York: PublicAffairs.

Murthy, D. (2013). Twitter: social communication in the Twitter age.

Pavani, M. (2019). \#MeToo movement: Not all men are guilty, not all women are victims. [online] The Financial Express. Available at: https://www.financialexpress.com/india-news/metoo-movement-not-all-men-are-guilty- 
not-all-women-are-victims/1359967/ [Accessed 16 Jul. 2019].

Penney, J., \& Dadas, C. (2014). '(Re)tweeting in the service of protest: Digital composition and circulation in the Occupy Wall Street movement.' New Media \& Society, 16(1), 74-90. doi:10.1177/1461444813479593

McCarthy, John D., and Mayer N. Zald. 1977. 'Resource Mobilization and Social Movements: A Partial Theory.' American Journal of Sociology 82(6):1212-41.

Selander, S., and Jarvenpaa, L. 2016. 'Digital action repertoires and transforming a social movement organization'. MIS Quarterly Vol. 40 No. 2, pp. 331-352

Shirky, C. (2008) 'Here Comes Here Comes Everybody', IEEE Spectrum, 45(9), pp. 2324. doi: $10.2307 / 3853272$.

The Wire. (2019). Government Forms Group of Ministers to Look into Sexual Harassment at Workplace. [online] Available at: https://thewire.in/women/governmentforms-group-of-ministers-to-look-into-sexual-harassment-at-workplace

Toepfl F and Piwoni E (2017) Targeting dominant publics: how counterpublic commenters align their efforts with mainstream news. New Media \& Society 20: 20112027

Wolfsfeld, G., Segev, E. and Sheafer, T. (2013) 'Social Media and the Arab Spring: Politics Comes First', International Journal of Press/Politics, 18(2), pp. 115-137. doi: $10.1177 / 1940161212471716$

\section{Author biographies}

Chindu Sreedharan is a principal academic in Journalism at Bournemouth University. $\mathrm{He}$ is a former journalist and has a particular interest in journalistic storytelling as a means to improve human rights situations and empower marginalised groups. His research focuses on 'abnormal' journalisms', reportage that extends the boundaries of conventional newswork-from crisis and post-disaster situations, on social media, as well as new forms of nonfictional narratives. He is Co-Principal Investigator for Media Action Against Rape (MAAR). He tweets @chindu

Einar Thorsen is an associate professor of Journalism and Communication, and Deputy Dean of Research and Professional Practice for the Faculty of Media and Communication at Bournemouth University. His research concerns online journalism, citizens' voices, and news reporting of crisis and political change-linked with protecting freedom of speech, human rights, and civil liberties-especially for journalists, 
vulnerable people, marginalised groups, and in contexts or countries where such liberties are being curtailed. He tweets @einarthorsen

Ananya Gouthi is a research assistant for the Media Action Against Rape, led by Bournemouth University and UNESCO, New Delhi. She graduated from the Symbiosis School for Liberal Arts, Pune, majoring in Media Studies with a minor in International Relations. Ananya is most driven by work that explores (and aims to dismantle) the various structural inequalities present in the world we live. 